\title{
Incontinent Epispadias
}

National Cancer Institute

\section{Source}

National Cancer Institute. Incontinent Epispadias. NCI Thesaurus. Code C123178.

Epispadias with urinary incontinence. 